\title{
Sputum Cultures and Clinical Interpretation in the Management of Acute Pulmonary Attacks in a Child with Cystic Fibrosis
}

\author{
Kistik Fibrozisli Bir Çocukta Akut Akciğer Atağının Yönetiminde Balgam Kültürleri \\ ve Klinik Yorumlanması
}

\author{
Fatma Dilşad Aksoy(ID), Mustafa Hacımustafaoğlu(ID) \\ Division of Pediatric Infectious Diseases, Department of Pediatrics, Uludag University Faculty of Medicine, Bursa, Turkey
}

Questions: The interrelated questions are summarized as follows. And the answers are shared.

1) When the sputum culture were not available in a child with cystic fibrosis, would it be appropriate to take a throat culture in spite of sputum culture?

2) Is it appropriate not to begin the treatment until the sputum culture results available in an afebrile child with cystic fibrosis?

3) Is it necessary to take a control sputum culture during or at the end of the treatment? If it is yes, when should it be taken?

4) How should the treatment be managed if the sputum culture taken is resistant to the given treatment?

(The questions came from different physicians)

Cite this article as: Aksoy FD, Hacımustafaoğlu M. Sputum cultures and clinical interpretation in the management of acute pulmonary attacks in a child with cystic fibrosis. J Pediatr Inf 2021;15(2):e119-e121.

\section{Answers (Fatma Dilşad Aksoy, MD; Mustafa Hacımustafaoğlu, MD)}

Introduction and general information: In the treatment approach of pulmonary infection attacks in cystic fibrosis (CF), almost all guidelines recommend appropriate antibiotic therapy for bacteria grown in the culture of respiratory secretions (sputum). CF patients often carry the same bacteria in their airways for a long time. According to the guidelines of the Cystic Fibrosis Foundation, sputum or throat swab cultures are recommended every three months on average during routine clinical visits. These cultures are relatively consistent with culture results obtained during a recent episode of lung infection. Almost all guidelines recommend the selection of antibiotics with efficacy against pathogenic bacteria growing in the patient's recent respiratory tract/secretion cultures in the treatment of acute pulmonary attacks. Therefore, if the bacteria that grow in respiratory secretions have not changed since the last attack, it makes sense to apply the same antibiotic therapy that was successful before. The antibiotic treatment selected at the beginning of the attack is changed only if the clinical response is insufficient, and new cultures are taken to guide the therapy. If a routine culture has not been performed within a few weeks prior to the onset of an acute attack, it is usually appropriate to take the sputum culture, begin the ampiric therapy, and act according to the clinical outcome and culture results.

\section{Correspondence Address / Yazışma Adresi}

Mustafa Hacımustafaoğlu

Uludağ Üniversitesi Tıp Fakültesi,

Çocuk Sağlığı ve Hastalıkları Anabilim Dalı,

Çocuk Enfeksiyon Hastalıkları Bilim Dalı,

Bursa-Türkiye

E-mail: mkemal@uludag.edu.tr 
Traditional approach to treating CF pulmonary exacerbations; antibiotic treatment is given according to the recent culture antibiogram results. Traditionally, culture antibiogram results are expected to be directly compatible with clinical success. However, increasing evidence has shown that selecting antibiotics based on antibiogram susceptibility testing, especially for Pseudomonas aeruginosa, may not improve the clinical outcome results significantly. This has led some CF centers to reduce the frequency of routine antibiotic susceptibility testing for $P$. aeruginosa from once every three months to once a year.

In a meta-analysis planned to evaluate whether the clinical response to antibiotics given in lung attacks is consistent with the results of antibiotic susceptibility test. Of the 13 studies evaluated, 11 failed to show that antibiotic sensitivity results in sputum culture predicted clinical response. However, most of the studies covered in this systematic review evaluated patients infected with $P$. aeruginosa. For other CF bacteria; the data required to evaluate the value of the antibiotic susceptibility test are insufficient to make any meaningful interpretation. Therefore, it will be appropriate to use susceptibility test results for antibiotic selection for non-Pseudomonas bacteria until new literature evidence is available.

Especially for Pseudomonas, there are some reasons of the weak correlation with antibiotic susceptibility test results and clinical success in CF;

a) In studies where antibiotic susceptibility test results were repeated, significant differences were found when the same morphotype was tested multiple times even in the same laboratory, or when a single isolate was tested by more than one laboratory.

b) The same bacterial species obtained from different airway segments of the same patient may have different phenotypes, including different antibiotic resistance profiles. In addition, the airway environment (such as a thick mucus layer) of patients with CF is similar to the environment of biofilm-forming bacteria, and therefore the penetration of antibiotics into the infected mucoid issue and clinical treatment success may be lower than expected.

c) The culture conditions used by clinical microbiology laboratories are not exactly the same as the in vivo airway environment of CF patients. Bacteria may be sensitive to one particular antibiotic in one environment and not to be sensitive in another.

d) Microbiome studies, revealed that the diversity of bacteria in the airway of the patient with CF are much wider than defined by culture techniques. The role of previously unrecognized bacteria in pulmonary exacerbations and the level of their response to antibiotics for bacteria identified with standard cultures is unknown.
It is not unexpected for more than one bacteria to grow in acute lung attacks. CF guidelines recommend at least one antibiotic to cover every pathogenic bacteria cultured from respiratory secretions and dual antibiotics for $P$. aeruginosa infections. Evidence is lacking to support the use of dual antibiotics for Pseudomonas, although it has in fact been standard practice for many years; there is considerable debate about the pros and cons. CF guidelines do not recommend dual antibiotic administration for other gram-negative organisms other than pseudomonas, such as Achromobacter spp., Stenotrophomonas maltophilia.

While planning the lung attack treatment of a patient with $\mathrm{CF}$; if there is no culture and antibiogram available; the most probable factors leading to an acute lung infection attack (Pseudomonas in particular) should be considered, and rationally selected antibiotics should be taken into account for the initial therapy. Retrospective studies show that many patients will recover clinically with this rational empirical treatment. In the case of the susceptibility test results of $P$. aeruginosa are resistant to the given antibiotics, if clinical success has been achieved with the given antibiotics, the clinicians should not hesitate to continue the antipseudomonal antibiotics that the laboratory reported as resistant. Thus, if a patient is clinically improving following the initial antibiotics, it is recommended to continue treatment regardless of the resistance pattern reported from a sample obtained at the start of treatment. In a study in which 6451 pulmonary exacerbations were evaluated retrospectively in pediatric patients, it was reported that antibiotic change during treatment was more frequent when new culture antibiogram tests were performed. However, there was no evidence that it had a positive effect on the clinical course. If a patient does not show clinical improvement within about five days of starting treatment, it is appropriate to change antibiotic therapy. In this context, if the patient's clinical response is insufficient, a new treatment plan should be made, taking into account the results of antibiotic sensitivity, clinical features and other possible factors.

As a result, in the light of the general information mentioned above, the questions can be answered briefly as follows.

1) When we cannot get a sputum culture in a child with cystic fibrosis, would it be appropriate to take a throat culture and act accordingly? First of all, to take the sputum culture is preferred. However, this may not be possible always, especially in young children. In this case, a carefully taken throat culture can do the same. In some cases, it may be preferable to obtain induced sputum (after nebulized SF or hypertonic saline). However, during this procedure, it is important to carefully follow the contact and droplet isolation precautions to prevent contamination of other patients with possibly resistant agents. 
2) Is it appropriate to hold the treatment until the sputum culture is available in a child with cystic fibrosis without fever? Fever is generally not expected in acute pulmonary attacks in CF patients. In a patient with an acute attack, treatment should be started immediately. So, the result of a new sputum culture is not expected. If there is a sputum culture taken recently, treatment is started considering the agent growing and its antibiogram sensitivity. If there is no recent culture, a dual antibiotic treatment is started empirically and preferably covering pseudomonas. In this case, the culture results obtained during hospitalization are evaluated during follow-up. If the patient has an optimal clinical response, the empirical therapy that has already been started is continued.

3) Is it necessary to take a control sputum culture during and/or at the end of the treatment, if so, when should it be taken? If there is no sufficient clinical response to treatment within five days of the beginning treatment, a sputum culture can be obtained and treatment change can be made. If there is no clinical response to treatment, evaluation should also be made in terms of the presence and treatment of non-pseudomonas bacteria.

4) If the sputum culture taken towards the end of the treatment is resistant to the treatment given, how should the treatment be managed? In CF patients, bacteria showing different resistance characteristics may grow in the same regional cultures taken at different time periods. In addition, the the given antimicrobial agent and its antibiotic sensitivity may not always be in parallel with the clinical ground. Therefore, if a patient with CF has an optimal clinical response to therapy, a control sputum culture is not required. Even if the culture is taken and the antibiogram shows resistant pattern to the treatment initiated, it will be appropriate to continue the treatment in a patient with a clinical response.

\section{References}

1. Flume PA, Mogayzel PJ Jr, Robinson KA, Goss CH, Rosenblatt RL, Kuhn $R J$, et al. Cystic fibrosis pulmonary guidelines: treatment of pulmonary exacerbations. Am J Respir Crit Care Med 2009;180:802-8. [CrossRef]

2. Döring G, Conway SP, Heijerman HG, Hodson ME, Høiby N, Smythet $A$, et al. Antibiotic therapy against Pseudomonas aeruginosa in cystic fibrosis: a European consensus. Eur Respir J 2000;16:749-67. [CrossRef]
3. Lahiri T, Hempstead SE, Brady C, Cannon CL, Clark K, Condren ME, et al. Clinical practice guidelines from the cystic fibrosis foundation for preschoolers with cystic fibrosis. Pediatrics 2016;137:1-26. [CrossRef]

4. Antibiotic treatment for cystic fibrosis. In: Report of the UK Cystic Fibrosis Trust Antibiotic Working Group. $3^{\text {rd }}$ ed. 2009. [CrossRef]

5. Saiman L, Siegel J. Cystic Fibrosis Foundation Consensus Conference on Infection Control Participants. Infection control recommendations for patients with cystic fibrosis: microbiology, important pathogens, and infection control practices to prevent patient-to-patient transmission. Am J Infect Control 2003;31:7-17. [CrossRef]

6. Rosenfeld M, Davis SD, Sabadosa KA, Spear SL, et al. Cystic Fibrosis Foundation evidence-based guidelines for management of infants with cystic fibrosis. J Pediatr 2009;155:S73-93. [CrossRef]

7. Somayaji R, Parkins MD, Shah A, Martiniano SL, Tunney MM, Kahle JS, et al. Antimicrobial susceptibility testing (AST) and associated clinical outcomes in individuals with cystic fibrosis: a systematic review. J Cyst Fibros 2019;18:236-43. [CrossRef]

8. Foweraker JE, Laughton CR, Brown DF, Bilton D. Phenotypic variability of pseudomonas aeruginosa in sputa from patients with acute infective exacerbation of cystic fibrosis and its impact on the validity of antimicrobial susceptibility testing. J Antimicrob Chemother 2005;55:9217. [CrossRef]

9. Jorth P, Staudinger BJ, Wu X, Hisert KB, Hayden H, Garudathri J, et al. Regional isolation drives bacterial diversification within cystic fibrosis lungs. Cell Host Microbe 2015;18:307-19. [CrossRef]

10. Dales $L$, Ferris W, Vandemheen K, Aaron SD. Combination antibiotic susceptibility of biofilm-grown Burkholderia cepacia and Pseudomonas aeruginosa isolated from patients with pulmonary exacerbations of cystic fibrosis. Eur J Clin Microbiol Infect Dis 2009;28:1275-9. [CrossRef]

11. Huang YJ, LiPuma JJ. The microbiome in cystic fibrosis. Clin Chest Med 2016;37:59-67. [CrossRef]

12. Elphick $H E$, Scott A. Single versus combination intravenous anti-pseudomonal antibiotic therapy for people with cystic fibrosis. Cochrane Database Syst Rev 2016;12:CD002007. [CrossRef]

13. UpToDate. Simon RH. Cystic fibrosis: treatment of acute pulmonary exacerbations. Mallory GB, Edwards MS, Hoppin AG (eds). Available on: https://www.uptodate.com/contents/cystic-fibrosis-treatment-of-acute-pulmonary-exacerbations (Accessed date: 3 May 2021). [CrossRef]

14. Smith AL, Fiel SB, Mayer-Hamblett N, Ramsey B, Burns JL. Susceptibility testing of pseudomonas aeruginosa isolates and clinical response to parenteral antibiotic administration: lack of association in cystic fibrosis. Chest 2003;123:1495-502. [CrossRef]

15. Stanojevic S, McDonald A, Waters V, MacDonald S, Horton E, Tullis E, et al. Effect of pulmonary exacerbations treated with oral antibiotics on clinical outcomes in cystic fibrosis. Thorax 2017;72:327-32. [CrossRef]

16. Cogen JD, Whitlock KB, Gibson RL, Hoffman $L R$, VanDevanter DR, et al. The use of antimicrobial susceptibility testing in pediatric cystic fibrosis pulmonary exacerbations. J Cyst Fibros 2019;18:851-6. [CrossRef] 